This item was submitted to Loughborough's Research Repository by the author.

Items in Figshare are protected by copyright, with all rights reserved, unless otherwise indicated.

\title{
Emotions in a repeated cournot duopoly game: A psychophysiological experiment
}

\section{PLEASE CITE THE PUBLISHED VERSION}

http://dx.doi.org/10.1037/npe0000069

\section{PUBLISHER}

(c) American Psychological Association

\section{VERSION}

AM (Accepted Manuscript)

\section{PUBLISHER STATEMENT}

This work is made available according to the conditions of the Creative Commons Attribution-NonCommercialNoDerivatives 4.0 International (CC BY-NC-ND 4.0) licence. Full details of this licence are available at: https://creativecommons.org/licenses/by-nc-nd/4.0/

\section{LICENCE}

CC BY-NC-ND 4.0

\section{REPOSITORY RECORD}

Leppanen, Ilkka, and Raimo P. Hamalainen. 2019. "Emotions in a Repeated Cournot Duopoly Game: A Psychophysiological Experiment”. figshare. https://hdl.handle.net/2134/24113. 
Emotions in a Repeated Cournot Duopoly Game: A Psychophysiological Experiment

Ilkka Leppänen, Raimo P. Hämäläinen

Aalto University

Accepted manuscript, final version, Journal of Neuroscience, Psychology, and Economics November 10, 2016

Author Note

Ilkka Leppänen, Systems Analysis Laboratory, Aalto University, Espoo, Finland; Raimo P.

Hämäläinen, Systems Analysis Laboratory, Aalto University, Espoo, Finland.

Ilkka Leppänen is now at School of Business and Economics, Loughborough University, Loughborough, United Kingdom.

We wish to thank Juulia Happonen for research assistance, Mikko Viinikainen for help with the data processing, and Pentti Henttonen for aid with the measurement equipment.

Correspondence concerning this article should be addressed to Ilkka Leppänen, School of Business and Economics, Loughborough University, Loughborough LE11 3TU, United Kingdom, e-mail: i.leppanen@lboro.ac.uk. 


\begin{abstract}
The reason why cooperation occurs in repeated games has remained a puzzle. Earlier literature has maintained that reciprocal behavior that gives rise to cooperation can be entirely self-regarding. However, experimental evidence shows that reciprocal behavior is otherregarding in many one-shot games. This other-regarding behavior is believed to have an emotional foundation. We hypothesized that emotions play a role in reciprocal behavior in repeated games as well. We tested this hypothesis by measuring the psychophysiological correlates of emotions from pairs of subjects as they played a repeated Cournot duopoly game. The players, who were in different rooms and remained anonymous to each other, made adjustment decisions to their production quantities that determined their payoffs in each round. Autonomic nervous system arousal was activated when the payoffs of both players decreased in a round, whereas positive affect was expressed when the payoffs of both players increased in a round. The disgust expression was related to a player's own one-sided increase in the payoff. Anger was expressed occasionally but less frequently when the outcome was the player's ideal outcome. An upwards adjustment of the production quantity was observed when the other player did not cooperate. This had the effect of decreasing the payoffs of both players and this was also related to an increase in the level of arousal. Our results provide evidence on how emotions are present in reciprocal behavior in a repeated social dilemma game. The results challenge recent behavioral research that advocates self-regarded motivations of cooperation in repeated games.
\end{abstract}

Keywords: cooperation; games; emotions; psychophysiology 


\section{EMOTIONS IN A REPEATED COURNOT DUOPOLY GAME}

Emotions in a Repeated Cournot Duopoly Game: A Psychophysiological Experiment What is the role of emotions in cooperation in repeated games? Mounting experimental evidence from one-shot games shows that cooperative behavior is related to emotions (Camerer and Fehr, 2004; Camerer et al., 2005; Fessler and Haley, 2003; Haidt, 2007; Loewenstein et al., 2008; Phelps, 2009; Sanfey, 2007) despite of the fact that in one-shot games the players interact anonymously and expect to never meet again in the same situation. Research in behavioral economics has explained cooperation in one-shot games by the players' preferences for equity and fairness and the reciprocal punishment and reward strategies that arise from these preferences (Boyd et al., 2010; Fehr and Fischbacher, 2002; Sobel, 2005). The concepts of emotions and other-regarding preferences are two sides of the same coin. For example, unfair offers in the Ultimatum Game elicit the negative emotions of anger (Pillutla and Murnighan, 1996), sadness (Harlé and Sanfey, 2007), and disgust (Chapman et al., 2009).

The findings of emotional activity in cooperation in one-shot games cannot be generalized to repeated games. This is because of the Folk Theorem arguments that are most often used to explain behavior in repeated interaction. According to the Folk Theorem, reciprocal punishments and rewards that typically demonstrate other-regarding behavior in one-shot games can be part of an adaptive and rational response strategy and entirely self-regarding in repeated games (Fudenberg and Maskin, 1986). Therefore cooperative behavior in repeated games may not result at all from other-regarding motives. It could thus be hypothesized that due to these adaptive rational strategies emotions play a lesser role in repeated interactions than in one-shot interactions. However, it can equally well be hypothesized that cooperation in repeated games arises from emotional reactions that subjects experience when observing each others' strategy adjustments that lead to relative payoff changes -- we just cannot observe these motivations if we 


\section{EMOTIONS IN A REPEATED COURNOT DUOPOLY GAME}

are only observing behavior. This raises the need to study the processes behind the decisions, in addition to the decisions themselves.

To study the role of emotions in cooperation in repeated games, we arranged an experiment where we obtained physiological measurements of facial emotional expressions and autonomic nervous system (ANS) activity from subjects who played an indefinitely repeated Cournot duopoly game. Because of the relevance of emotions in motivation, we were especially interested in correlating emotional states with events in the game where the players observe how their payoffs change from one round to another. We also wanted to know how the measured emotional states correlated with the adjustment decisions that the players made in their strategies after observing the changes in payoffs.

We used the Cournot duopoly game to represent the social dilemma because this game allows a large strategy space but is otherwise qualitatively similar to the Prisoner's Dilemma and Public Goods games that are often used to model social dilemmas. The large strategy space allows separating intended reactions from mere adjustments (e.g. after erroneous choices) better than the commonly used $2 \times 2$ matrix of the Prisoner's Dilemma. To control for the presence of subjective ideal outcomes we privately asked from each subject their ideal outcomes and include these in the analysis. Our interest was not in the behavior as such, as behavioral aspects such as equilibrium convergence or learning in the repeated Cournot duopoly game and in other social dilemma games have been extensively analyzed in the previous literature, but in the emotional correlates of the behavior that we expected to include reciprocal adjustments.

During the game we measured emotional arousal by electrodermal activity indexed by the skin conductance response (SCR) that corresponds to activation of the sympathetic branch of the ANS. Facial expressions of anger, disgust, and positive affect were measured by specific forms 
of electromyographic (EMG) activation that indexes facial musculature movements. The distinction between the negative emotions of anger and disgust was important because these emotions are used interchangeably in everyday language (Nabi, 2002) making self-reports of them unreliable. We also recorded decision times to index cognitive system function and to complement the emotional measurements.

\section{The Cournot duopoly game}

In the experiment the players played the same Cournot duopoly game for 20 rounds with the same opponent. The psychophysiological measurements were obtained from both players simultaneously. The players remained anonymous to each other. During each round the players made production quantity decisions. The duration of the game was not known by the players beforehand. In other words, the game was indefinitely repeated.

The payoffs in the game were quadratic with zero production costs. The payoffs were given by the functions $x(a-x-y)$, where $x$ is the player's own production quantity, $y$ is the other player's production quantity, and $a=24$ is a parameter that describes market demand. The possible production quantities were integers 3 to 15 . The payoffs were presented in a payoff matrix (see Supporting Information). The game has a unique Nash equilibrium $x=y=8$ and a cooperative outcome, the symmetric joint-optimum $x=y=6$. The reaction functions are downward-sloping (Huck et al., 2001). This means that if the production quantities are higher than in the symmetric joint-optimum, then adjusting own production quantity downwards increases cooperation and adjusting it upwards decreases cooperation. If the other player has not cooperated but the player himself has, then an upwards adjustment can be interpreted as a punishment. A downwards adjustment can be interpreted either as a cooperative act if the other 


\section{EMOTIONS IN A REPEATED COURNOT DUOPOLY GAME}

player has acted similarly, or a corrective act if the other player has punished from not cooperating.

It is well known that subjects in experiments cooperate in indefinitely repeated Cournot duopoly games, i.e. they play outcomes that have higher payoffs than the payoffs given by the Cournot-Nash equilibrium (Holt, 1995; Potters and Suetens, 2013). Because the game we use is indefinitely repeated, any outcome that has better payoffs for both players than in the CournotNash equilibrium can be supported as the subgame-perfect equilibrium of the game if the players are patient enough (Schmalensee, 1988). Many experiments with this game have found that the players aim for the symmetric joint-optimum (Huck et al., 2001, 1999; Normann et al., 2014). However, it is possible that not all players view the symmetric joint-optimum the sole desirable outcome as there are 13 different production quantities and the payoff matrix has 169 different outcomes. We therefore also asked the subjects to state their "ideal" outcomes at the beginning of each round. This took into account the possibility that the players had subjective ideals (see e.g. Selten et al., 1997, for a similar procedure). The ideal outcomes were not communicated to the opponent. We use the ideal outcomes as additional control variables in the analysis.

\section{Hypotheses}

We hypothesize that emotional arousal and the facial emotional expressions activate in specific ways when the players observe changes in outcomes between the rounds. The first hypothesis concerns emotional arousal:

\section{Hla: Emotional arousal is activated whenever outcomes change.}

This hypothesis reflects the well-known role of emotional arousal in motivational activation when confronting changes in the environment as represented by meaningful stimuli (Bradley, 2008). In a repeated social dilemma a changing outcome alerts the player of a changing course of 


\section{EMOTIONS IN A REPEATED COURNOT DUOPOLY GAME}

the game. Because this change can be caused by either of the players, a heightened emotional arousal works as the alert signal that is raised by the autonomous nervous system that an action to repair or restore that change is needed.

Emotional arousal is, however, not enough to inform us about the motivational tendency, because it cannot distinguish between positively and negatively valenced motivational tendencies. Measuring two kinds of negative facial expressions allows us to evaluate the motivational tendency that is related to punishments and aversion. The anger expression is known to be approach motivated (Carver and Harmon-Jones, 2009) and the disgust expression withdrawal motivated (Chapman and Anderson, 2012). Thus we hypothesize that these two expressions activate in different situations and therefore also have different behavioral implications. ${ }^{1}$

H1b: Anger is activated only when the player loses and the other player gains.

\section{H1c: Disgust is activated in one-sided losses.}

Hypothesis H1c reflects the advantageous inequity aversion and disadvantageous inequity aversion components of the inequity aversion model of Fehr and Schmidt (1999). Thus we posit that disgust relates to two kinds of situations of inequity aversion. Aversion to disadvantageous inequity occurs when one is averse to own inequity, i.e. when one's own payoff decreases but the other player's payoff increases. Aversion to advantageous inequity occurs when one is averse to the other player's inequity, i.e. when the other's payoff decreases but own payoff increases. According to hypothesis $\mathrm{H} 1 \mathrm{~b}$ we expect the emergence of the anger expression only in situations of disadvantageous inequity. Therefore the anger emotion is only restricted to situations that

\footnotetext{
${ }^{1}$ However, the corrugator supercilii muscle that indexes anger may activate in the disgust expression alongside the levator labii that indexes disgust (Vrana, 1993). We ruled out this possibility in the analysis and considered only the cases where the different muscle areas were exclusively activated in their corresponding expressions.
} 


\section{EMOTIONS IN A REPEATED COURNOT DUOPOLY GAME}

potentially motivate the subject to approach the transgressor and respond by a reciprocal punishment.

Positive affect is not found to be affiliated with a motivational tendency (Fredrickson, 2001). However, based on earlier research on positive emotions in economic games (see e.g. Offerman, 2002; Xiao and Houser, 2005) we expect that

\section{H1d: Positive affect is activated in mutual gains or in one-sided gains.}

Hypothesis H1d includes the assumption that positive affect can activate also in situations where the player himself does not gain or lose but the other player gains. This hypothesis is therefore an opposite of hypotheses $\mathrm{H} 1 \mathrm{~b}$ and $\mathrm{H} 1 \mathrm{c}$ in the sense that those hypotheses assumed that the negative emotions of anger and disgust are related to decreases in payoffs, whereas H1d is related to increases in payoffs.

Dual-process models of decision making (Brocas and Carrillo, 2014; Loewenstein and O’Donoghue, 2004) argue that subjects who confront conflicting objectives resolve these conflicts by using either controlled or automated responses. In social dilemma games the conflicting objectives of one-sided and mutual gains are, by definition, always present. Especially in the situation where the other deviates from cooperation, one is conflicted between maintaining the cooperative strategy and making a costly punishment. In our case the player can resolve to the noncooperative Nash outcome by making a small quantity adjustment from 6 to 8 . This however is not enough for a punishment because the resulting payoff reduction is only 8 units to the other player. Punishing with a large quantity adjustment from 6 to 10 or more is costly for both as it leads to a larger payoff reduction. We thus form the hypothesis that the size of the upwards adjustment in the production quantity is modulated by emotional arousal (which is a correlate of automated processing) during decision making: 


\section{EMOTIONS IN A REPEATED COURNOT DUOPOLY GAME}

H2a: The adjustment after the other's defection is the higher the higher is the level of emotional arousal.

This hypothesis suggests that the size of the adjustment, i.e. the severity of the punitive action after the other's defection, is the higher the higher emotional arousal is when making that adjustment. On the other hand, the conflict between one-sided and mutual gains is present also when the subject himself is tempted to defect from cooperation. Here the conflict arises because the instant payoff from defection is large compared to the payoff that is available from the cooperative outcome. Therefore we also hypothesize that

$H 2 b:$ The adjustment after a cooperative outcome is the higher the higher is the level of emotional arousal.

Decision time has previously been used to measure the involvement of the intuitive system in decision making (see e.g. Piovesan and Wengström, 2009). As an additional variable we also measured decision times and correlated these with the adjustments. Our original aim was to gain insight into how the intuitive system participates in strategy adjustments. However, recently Evans et al. (2015) and Krajbich et al. (2015) have argued that fast decision times reflect low level of decision conflict rather than intuitive decision making. We therefore only report the results of decision time correlations but do not include them in any specific hypotheses, as our large matrix design is not particularly suitable for measuring conflicted alternatives with dichotomous regressors (i.e. conflicted vs. unconflicted decisions).

\section{Materials and Methods}

\section{Task structure}

Each round of the duopoly game consisted of seven stages that were either self-paced or paced by the computer: 


\section{EMOTIONS IN A REPEATED COURNOT DUOPOLY GAME}

1. Indicate an ideal outcome cell in the payoff matrix (self-paced).

2. Wait 10 seconds.

3. Choose the production quantity (self-paced).

4. Confirm the production quantity or return back to choosing it (self-paced).

5. Wait 10 seconds or more if the other player has not yet confirmed.

6. View outcomes (self-paced).

7. Wait 10 seconds.

The payoff matrix was displayed at all times except at the wait stages. A table with outcomes and own ideal outcomes from all previous rounds was displayed whenever the payoff matrix was displayed. The ideal outcomes for the round were highlighted at the payoff matrix at each round. See the Supporting Information for the payoff matrix, experiment instructions, and screenshots from the experimental interface.

\section{Psychophysiological measurements}

The measurements were recorded in continuous time using bipolar $\mathrm{Ag} / \mathrm{AgCl}$ surface electrodes attached to the subjects' medial phalanges of the volar surfaces of left hand middle and ring fingers (for SCR) and in 3 muscle regions on the left hemisphere of the face (for EMG). These regions were the corrugator supercilii (corresponding to the anger expression), the levator labii superioris (disgust), and the zygomaticus major (positive affect) muscle regions. The electrode placements were as recommended by Fridlund and Cacioppo (1986). Before the SCR electrodes were attached into their medial phalanges of left hand index and middle fingers, the subjects washed their hands with neutral soap. Before the EMG electrodes were attached into the subjects' facial muscle regions, the regions were cleansed with alcohol, abraded slightly, and then cleansed again with water. The measurements were recorded with NeXus-4 devices 
(MindMedia B.V., The Netherlands) and the signals were recorded with BioTrace+ software (MindMedia B.V., The Netherlands). Post processing was conducted in MatLab (Mathworks Inc., MA, USA) and the R environment (R foundation, Austria). The experiment was approved by the ethics committee of Aalto University and conducted in accordance with the principles of the Declaration of Helsinki. The measurements were noninvasive and harmless and did not require medical consultation.

\section{Subjects and rewarding}

Altogether 44 healthy subjects ( 24 female), or 22 pairs, participated. The subjects were Finnish speaking and the experiment was conducted in Finnish. The mean age of the subjects was 26.1 years. All subjects were at least 20 years old and six subjects were more than 30 years old. All subjects were right-handed computer mouse users. The subjects received a cinema voucher, worth EUR 11, as a show-up fee, and a monetary reward based on their success on two randomly selected rounds. The mean monetary reward was EUR $11.30 \pm 3.90(S D)$. The lowest monetary reward was EUR 1.50 and the highest monetary reward was EUR 17.20. A typical length of the whole experimental session was 70 minutes.

\section{The laboratory procedure}

Two subjects at a time participated in the experiment. We went to great lengths in ensuring that the subjects remained anonymous to each other, and this was also made clear at their invitations. The experimenters picked up the subjects from the opposite entrances of a large university building and timed the arrivals to the laboratory so that the subjects had no possibility to confront each other. The two experimenters (male and female) were present when the subjects were prepared and when the experiment ended. After the experiment the subjects were instructed to leave at different times and use separate exits. The subjects were placed in separate silent and 


\section{EMOTIONS IN A REPEATED COURNOT DUOPOLY GAME}

dimly lit rooms where the experiment took place. They sat in standard office chairs in front of adjustable computer tables and used only the computer mouse with their right hands to control the decision making during the game. To exclude movement artifacts in the SCR data, the subjects' left hands were gently attached to the table with soft medical tape. Before starting the experiment, a preparation that lasted 15 minutes took place, during which the experimenters elicited written consent, attached the measurement devices, and introduced the subjects to the rules of the game. The experiment lasted for 20 rounds, but the duration was not known by the subjects before round 20 had ended. ${ }^{2}$ The subjects were inquired after the experiment whether they suspected having fake opponents, but no one suspected this.

\section{SCR analysis}

The 128-Hz SCR data was analyzed using a deconvolution method where the SCR signal component of interest, the phasic SCR, was extracted from the tonic SCR component (Benedek and Kaernbach, 2010). The method views the skin conductance activity as a convolution of a driver function and an impulse response function (IRF), where the IRF is common to both components, and the driver represents the phasic SCR, i.e. sudomotor nerve activity controlled by the sympathetic ANS. Before the deconvolution procedure, the raw data was downsampled to $64 \mathrm{~Hz}$ and smoothed in a Gaussian window with a width of 16 samples. The IRF is represented by a biexponential Bateman function that has two goodness-of-fit parameters that were obtained by numerical optimization using MatLab (Mathworks Inc., MA, USA). Deconvolution methods detect SCRs better than the standard method of through-to-peak analysis where local maxima and minima are searched (Benedek and Kaernbach, 2010). Such peaks may be undetectable if the

\footnotetext{
${ }^{2}$ This termination rule was employed for its simplicity. Other repeated duopoly experiments that use the same rule include Mason and Phillips (1997) and Rassenti et al. (2000). There are, however, other types of termination rules in the literature that better control beliefs, such as a probabilistic rule and a rule in which the subjects know exactly the terminal round. For discussion of the different rules, see Roth and Murnighan (1978), Roth (1995), and Huck et al. (2004).
} 


\section{EMOTIONS IN A REPEATED COURNOT DUOPOLY GAME}

SCRs are superposed, leading to underestimation of SCR amplitudes (Society for

Psychophysiological Research, 2012). The arousal score was formed by integrating the deconvoluted SCRs over a 5-s time window that starts $1 \mathrm{~s}$ after the beginning of the result stage. This integrated SCR score was then divided by the window length in seconds to obtain the score in $\mu \mathrm{S}$ (microsiemens). Emotional arousal during decision making was measured from SCR during the consecutive choice, confirm, and wait stages, i.e. the stages that preceded viewing the results from the round. The emotional arousal score during decision making was formed by summing the amplitudes that occur within the choice, confirm and wait stages, and dividing this sum by the number of SCRs that occurred during those stages. The arousal scores were logarithmized.

\section{EMG analysis}

The 2048-Hz EMG data was band-pass filtered offline between $100 \mathrm{~Hz}$ and $500 \mathrm{~Hz}$, fullwave rectified, and moving-averaged within a 10-ms window. The EMG score was formed from the processed signal by taking a mean over the 6-s time window that began when the results were displayed. The baseline signal, obtained from a 6-s interval before the results were displayed, was subtracted from this score. After this the score was logarithmized. To reduce the possibility of cross-correlation between the muscle regions and thus of inflating Type-I error rates, the score was transformed into a count score where a count was registered if the specific EMG score corresponding to the muscle region was $>0 \mu \mathrm{V}$ (microvolts) while the scores of the other muscle regions were $<0 \mu \mathrm{V}$. For example, the count score for the levator labii (disgust) was 1 if and only if the score for levator labii was $>0 \mu \mathrm{V}$ while the scores for the corrugator supercilii (anger) and the zygomaticus major (positive affect) were $<0 \mu \mathrm{V}$. 


\section{Decision times}

The decision times were the time intervals with varying lengths that began from the choice of the production quantity and ended when choice was confirmed. The recorded decision times were logarithmized.

\section{Results}

The first round was discarded from all results analyses. One subject out of 44 was discarded from all results, except from the behavioral results, due to a hardware failure. Additionally, 5 subjects in the SCR measurements were discarded from the final results on emotional arousal. For these subjects the SCR signal either completely failed to appear, or failed to appear at some point during the experiment. The hardware failures did not affect how the experiment was conducted nor how the other measurements proceeded. Statistical analyses were conducted using linear mixed models (LMMs) and generalized linear mixed models (GLMMs) where the between-subject variance was modeled by including the subjects as random effects. The random effects are reported as $\sigma_{\mathrm{b}}$, the between-subject $S D$, alongside the residual $S D \sigma$. The analyses on the production quantity adjustments and SCR modeled temporal correlation of the decisions (see e.g. Normann et al., 2014; Zwick and Rapoport, 2002) using an AR(p) withinsubject correlation structure, where $p$ denotes the lag index and $\varphi_{1}, \ldots, \varphi_{p}$ are the parameters to be estimated.

\section{Behavior}

There was roughly at least a $10 \%$ share of each quantity 6 to 11 (Figure 1 ). The frequency of the symmetric joint-optima was low, as only 40/418 rounds resulted in the joint-optimum and only $3 / 22$ pairs stayed at the joint-optimum for more than 2 consecutive rounds. The players were less cooperative than in the literature. As a comparison, in the repeated Cournot duopoly 
experiment of Huck, Müller, and Normann (2001) the mean production quantity was $7.6 \pm 2.04$ $(S D)$. The mean cooperation index ${ }^{3}$ was $-0.18 \pm 0.87(S D)$, clearly lower than in the literature (Huck et al., 2001; Potters and Suetens, 2009).

There was a higher proportion of ideal joint-optimum outcomes, 206/836, than actual joint-optimum outcomes. In 153/836 cases the outcome was equal to the ideal outcome.

However, there were far more cases, 436/836, where the player's own quantity equalled his own ideal quantity but the other's quantity did not equal the ideal quantity set to the other. Overall, as the ideal other's quantities were lower than the actual other's production quantities (Figure 1), the payoff differences in the ideal outcomes were larger than in the actual outcomes. The mean ideal other's quantity increased $0.044 \pm 0.015$ (SEM) units during each round (LMM with round as the single fixed effect, $\left.t(791)=2.99, P=0.0029, \sigma_{\mathrm{b}}=1.28, \sigma=1.76, \varphi_{1}=0.34\right)$ whereas the mean ideal own quantity did not change in time (LMM with round as the single fixed effect, $\left.t(791)=-1.48, P=0.14, \sigma_{\mathrm{b}}=1.57, \sigma=1.68, \varphi_{1}=0.36\right)$. As the ideal other's quantity increased and the ideal own quantity remained unchanged, the ideal outcomes became more equal in payoffs in time.

Studying how the payoffs changed in a round we found that the production quantity was adjusted upwards on round $t+1$ if the other player had gained between rounds $t-1$ and $t$ (Figure 2) but the player himself had not gained. In the other cases the production quantity was adjusted downwards on round $t+1$. These cases were when both lost, when the player gained only himself, and when both gained.

${ }^{3}$ The cooperation index $\rho=\left[\left(x_{1}+x_{2}\right) / 2-x_{\mathrm{N}}\right] /\left(x_{\mathrm{J}}-x_{\mathrm{N}}\right)=4-\left(x_{1}+x_{2}\right) / 4$, where $x_{\mathrm{N}}=8$ is the Cournot-Nash production quantity and $x_{\mathrm{J}}=6$ is the joint-optimum production quantity. The cooperation index varies between -1 and 1 , and $\rho=1$ for the joint-optimum outcome, $\rho=0$ in the Cournot-Nash outcome, and $\rho=-1$ in the case where competition is perfect, i.e. where price equals marginal cost (Potters and Suetens, 2009). 


\section{EMOTIONS IN A REPEATED COURNOT DUOPOLY GAME}

\section{Emotional reactions to outcomes}

Emotional arousal was activated when players mutually lost with respect to previous round payoffs (Figure 2). Emotional arousal was not activated on viewing outcomes where players mutually gained or where players had one-sided gains or losses.

The disgust and positive affect expressions were activated on viewing changes in the

results in a round (Figure 3). The disgust expression was activated more frequently (Probit score larger than zero) when there was an own gain than in other situations, and less frequently (Probit score smaller than zero) when both lost than in other situations. The positive affect expression was activated more frequently (Probit score larger than zero) when both gained than in other situations, and less frequently (Probit score smaller than zero) when the other gained than in other situations.

The anger expression was not activated differentially in the situations where payoffs changed (Probit scores not different from zero, Figure 3). However, we found that the anger expression was related to observing that the outcome equalled the ideal outcome: The anger expression was activated less frequently (Probit score $-0.89 \pm 0.42(S E M))$ when the ideal outcome was equal to the outcome than when it was not (updated GLMM from Figure 3 with the added fixed interaction effect between two dichotomous dummy variables, whether the ideal outcome was equal to the outcome or not and choosing own ideal or not, $Z$-value $-2.12, P=$ 0.034). The disgust and the positive affect expressions were not activated in this situation ( imilar analysis as with anger; disgust $Z$-value $-0.34, P=0.73$; positive affect $Z$-value $-0.82, P$ $=0.41)$. To corroborate that an emotional reaction was indeed elicited when observing that the outcome was equal to the ideal outcome, we observed that ISCR increased in the log-scale by $0.076 \pm 0.034(S E M) \mu \mathrm{Ss}$ when the other player's quantity was equal to the ideal quantity from 
$0.31 \pm 0.056 \mu \mathrm{Ss}$ when the other player's was not equal to the ideal quantity (LMM with a dichotomous fixed effect, restricting to those subjects who chose their ideal production quantity, $\left.N=535, t(496)=2.23, P=0.026, \sigma_{\mathrm{b}}=0.062, \sigma=0.066, \varphi_{1}=0.42\right)$.

\section{Emotional activity during decision making}

Emotional arousal during the result-viewing stage of round $t-1$ was reasonably well correlated with arousal during decision making on round $t$ (Pearson's product-moment correlation coefficient $0.61, t(720)=20.53, P<0.001)$. This implies that the emotional activity when viewing the outcomes may have still influenced decision making on the next round.

To study how emotional activity specifically related to the production quantity adjustments on round $t$ we formed an LMM with two continuous covariates, emotional arousal and decision time during decision making on round $t$. Decision time was included to indirectly represent the cognitive system activity (Elster, 1998; Krajbich, Oud, and Fehr, 2014). Three dichotomous contrasts were then used to form interaction terms with the covariates. These were: the case where the player himself had cooperated but the other had not, i.e. $x_{i}=6$ and $x_{j} \geq 8$ on round $t-1(64 / 836$ such cases in total); the case where both players had cooperated, i.e. where $x_{i}, x_{j}=6$ on round $t-1(76 / 836$ cases $)$; and the case where the outcome was equal to the ideal outcome on round $t-1$ (138/836 cases). The latter case was included to control for a possible motivation to adjust based on the ideal outcome. The estimation results show that the adjustments were related to emotional arousal but not to decision time (Table 1). The interaction effects show that after the other had not cooperated the upwards adjustment was the higher the higher the level of emotional arousal was. There were no significant interaction effects relating to the 2 other contrasts, i.e. the cases of both cooperating on the previous round or having an outcome equal to the ideal outcome on the previous round. 


\section{EMOTIONS IN A REPEATED COURNOT DUOPOLY GAME}

\section{Discussion}

Repeated social dilemma games have for long been of interest to behavioral and experimental economists. Fouraker and Siegel, early researchers in this field, argued that in the repeated Cournot duopoly game there are players who care about fairness and reciprocity (Fouraker and Siegel, 1963). In addition to "the self-regarding maximizer" there is "the rivalist" who "derives satisfaction from reducing the gain accorded to the opposition and desires to surpass his rival" and "the cooperator who makes rewarding choices either in hopes of enhancing his own profits in the long run or because he derives satisfaction from the prosperity of his opponent."

Although cooperative behavior was clearly less frequent in our experiment than in comparable experiments in the literature, ${ }^{4}$ the players did use adjustments to correct for relative changes in payoffs between the rounds. The analysis of decisions showed that the players used upwards adjustments after the other's one-sided gain in payoffs between the rounds, downwards adjustments after an own one-sided gain or mutual losses, and downwards adjustments after mutual gains. The upwards adjustment after the other's one-sided gain can be interpreted as a punishment. These results are similar to other experiments with repeated social dilemma games and they demonstrate that players generally aim for cooperative outcomes by reciprocal decisions. These adjustments form the behavioral basis for our psychophysiological measurement correlations.

Hypothesis H1a concerning emotional arousal is supported. Emotional arousal as represented by autonomic activity during the results viewing stage was activated in mutual losses in a round. This result is in line with other studies evidencing that the ANS reacts to decision

\footnotetext{
${ }^{4}$ The relative infrequency of joint-optima can be possibly attributed to the social distance between our experimental subjects (Akerlof, 1997). In contrast to typical classroom experiments, the two subjects did not see each other before nor after the experiment.
} 


\section{EMOTIONS IN A REPEATED COURNOT DUOPOLY GAME}

outcomes (Ben-Shakhar et al., 2007; Dunn et al., 2012; Joffily et al., 2014; Sanfey et al., 2003; van't Wout et al., 2006). In our setting this possibly indicates that the players view mutual losses as the most alerting events in the course of the game, and that the ANS responses to other events (mutual gains and one-sided losses and gains) remain undetected in our study. We could also speculate, contrasting the mutual losses to situations with payoff gains, that the ANS response in the mutual losses situation is indicative of loss aversion where the experience of a loss is stronger than the experience of a comparable gain (Kahneman and Tversky, 1984). In earlier studies ANS activity has also been associated with loss aversion (Hochman and Yechiam, 2011; SokolHessner et al., 2009). It has been suggested that loss aversion has deep evolutionary origins in the emotional system of the brain, mainly in the amygdala (Camerer, 2005; De Martino et al., 2010). However, our experimental setting is not well suited for testing the psychophysiological basis of loss aversion in games.

We found that the disgust expression was activated when observing one-sided own gains in payoffs in a round. This supports Hypothesis H1c. This finding complements the understanding gained in previous research of how the disgust emotion can arise in strategic decision making. In addition to being a response to unfairness (Chapman et al., 2009), the disgust emotion can arise when observing that one has been unfair himself. These findings are in agreement with the theories of inequity aversion (Bolton and Ockenfels, 2000; Fehr and Schmidt, 1999) where humans are predicted to be averse not only to disadvantageous payoff distributions but also to advantageous payoff distributions. Our study indicates that disgust is the basic human aversive emotion that shows up when payoff distributions are unequal.

The emergence of disgust when one has unilaterally gained is a novel result. This situation represents aversion to advantageous inequity (Fehr and Schmidt 1999), i.e. aversion of 


\section{EMOTIONS IN A REPEATED COURNOT DUOPOLY GAME}

situations where one is at a payoff advantage relative to the other. However, this aversive reaction to advantageous inequity has a clear evolutionary foundation. A situation of advantageous inequity is likely followed by a costly punishment from the other player, and this costly punishment leads the pair to worsening payoffs. Therefore the disgust expression alerts the player from ending up into a situation where the players move further away from the cooperative outcome.

It is also noteworthy that the activation frequency of the disgust expression was reduced on viewing results where both players lost payoffs in a round. As the disgust expression is not known to be reciprocally activated on negative and positive valence (i.e. heightened in the former and inhibited in the latter with respect to the baseline), it is possible that the finding of reduced disgust frequency was caused by crosstalk due to volume conduction (Van Boxtel, 2010) with some other facial expression to which the activation of the orbicularis occuli muscle region that shares close proximity with the levator labii (Tassinary et al., 2007) is specific.

The positive affect expression was activated when observing mutual gains in payoffs and inhibited when observing the other's one-sided gains in payoffs in a round. This result supports Hypothesis H1d and is a clear demonstration of the involvement of positive affect in cooperation where increases in cooperation are experienced pleasantly and decreases unpleasantly. However, some other studies argue that the positive affect expression cannot be reciprocally activated in pleasant vs. unpleasant stimuli (Larsen et al., 2003), as it did in our study. These arguments are based on experimental evidence as well as on the neurophysiology of the zygomaticus major. The possibility that our result is explained by crosstalk is smaller in the positive affect expression than in the disgust expression, because the zygomaticus major muscle area is distinct from the 


\section{EMOTIONS IN A REPEATED COURNOT DUOPOLY GAME}

orbicularis occuli and because our EMG scoring method reduces these crosstalk effects between the disgust and positive affect expressions.

Unlike the disgust and positive affect expressions, the anger expression was not activated when observing changes in the outcomes in a round. Therefore we do not find support for Hypothesis H1b. In light of the support that we gained for the role of the disgust expression (Hypothesis H1c) this is not surprising: disgust and anger are, after all, differently motivated emotions. Together the support for hypothesis $\mathrm{H} 1 \mathrm{~b}$ and nonsupport for hypotheses H1c indicates that the emotion behind aversion to inequitable payoff distributions is disgust and not anger.

However, we did find that anger was less often expressed when the outcome was equal to the ideal outcome than when it was not. This finding possibly reflects the role of anger in restoring a state that is viewed desirable (Carver and Harmon-Jones, 2009; Fischer and Roseman, 2007). It also demonstrates the known pattern where, in addition to being increased in unpleasant stimuli, activity in the corrugator supercilii is decreased from the baseline in pleasant stimuli (Cannon et al., 2011; Larsen et al., 2003). In light of this evidence, the subjects experienced reaching the ideal outcomes pleasantly.

Our results support Hypothesis $\mathrm{H} 2 \mathrm{a}$ on the relationship between a punitive adjustment and emotional arousal but not Hypothesis $\mathrm{H} 2 \mathrm{~b}$ which states that a defective adjustment increases in emotional arousal. From the literature we can draw two possible roles for the emotional system in our setting. Emotional arousal arises when either the subject punishes the other of not cooperating, or when the subject himself does not cooperate and suffers the emotional consequences (Sütterlin et al., 2011). Our evidence points to the former role. The upwards adjustment in production quantity increased in emotional arousal after the other had not cooperated. This implies that the emotional system was involved in the decision to incur an 
upwards adjustment that can be seen as a punishment of not cooperating. The results are a possible sign of prefrontal inhibition, i.e. decreased top-down cognitive control of goal-directed action (Miller and Cohen, 2001; Ochsner et al., 2012). After the other player had not cooperated, low or non-existent emotional activity was related to not making an adjustment or to making only a small upwards adjustment to trigger to the noncooperative equilibrium. High emotional activity was related to making a large upwards adjustment that is costly for both players. Hence, the upwards adjustment in production quantity was evidently correlated with the level of emotional activity and was not part of a completely rational strategy.

As a summary of the results, we find that emotional arousal can act as an alert signal of mutual losses due to diminishing cooperation. Positive affect indicates enjoyment of establishing mutual gains when the players move towards the cooperative outcome. Disgust relates to aversion of advantageous inequity, i.e. aversion of situations where one is better off than the other. Our final observation is that arousal is related to costly punishment, implying that automated processing (as indicated by the level of arousal) is in an important role not only in the motivations for actions but also in the action itself. We conclude that cooperative behavior in the repeated Cournot duopoly game that our subjects played clearly has an emotional basis.

\section{Conclusions}

By correlating psychophysiological measurements with the analysis of decisions that the players make we demonstrate how emotions are involved as process measures in decision making in a social dilemma game. We found that emotional arousal was elicited when both players lost in payoffs, the positive affect expression was displayed when both players gained in payoffs, and the disgust expression was displayed when only the player himself gained in payoffs in a round. We also found that an upwards adjustment resulted after the other player had 


\section{EMOTIONS IN A REPEATED COURNOT DUOPOLY GAME}

not cooperated. The size of this adjustment correlated with the level of emotional activity in the ANS. The results shed light on the question of what motivates cooperative behavior in repeated interactions and demonstrably disagree with the idea that behavior in a repeated social dilemma game is adaptive and strategic and devoid of emotions. The results also disagree with the claim

provided by recent behavioral experiments (Cabral et al., 2014; Dreber et al., 2014; Reuben and Suetens, 2012) that cooperation in repeated games is mainly driven by self-regarding motives. 


\section{References}

Akerlof, G.A. (1997). Social distance and social decisions. Econometrica, 65, 1005-1027.

Bechara, A., \& Damasio, A. (2005). The somatic marker hypothesis: a neural theory of economic decision. Games and Economic Behavior, 52, 336-372.

Benedek, M., \& Kaernbach, C. (2010). A continuous measure of phasic electrodermal activity. Journal of Neuroscience Methods, 190, 80-91.

Ben-Shakhar, G., Bornstein, G., Hopfensitz, A., \& van Winden, F. (2007). Reciprocity and emotions in bargaining using physiological and self-report measures. Journal of Economic Psychology, 28, 314-323.

Bolton, G.E., \& Ockenfels, A. (2000). ERC: A theory of equity, reciprocity, and competition. The American Economic Review, 90, 166-193.

Boyd, R., Gintis, H., \& Bowles, S. (2010). Coordinated punishment of defectors sustains cooperation and can proliferate when rare. Science, 328, 617-620.

Bradley, M. (2008). Natural selective attention: Orienting and emotion. Psychophysiology, 46, $1-11$.

Brocas, I., \& Carrillo, J. (2014). Dual-process theories of decision-making: A selective survey. Journal of Economic Psychology, 41, 45-54.

Cabral, L., Ozbay, E., \& Schotter, A. (2014). Intrinsic and instrumental reciprocity: An experimental study. Games and Economic Behavior, 87, 100-121.

Camerer, C. (2005). Three cheers - psychological, theoretical, empirical - for loss aversion. Journal of Marketing Research, 42, 129-133.

Camerer, C., \& Fehr, E. (2004). Measuring social norms and preferences using experimental games: A guide for social scientists. In Henrich, J. et al. (Eds.), Foundations of Human 


\section{EMOTIONS IN A REPEATED COURNOT DUOPOLY GAME}

Sociality: Economic Experiments and Ethnographic Evidence from Fifteen Small-Scale Societies (pp. 55-95). Oxford, UK: Oxford University Press.

Camerer, C., Loewenstein, G., \& Prelec, D. (2005). Neuroeconomics: How neuroscience can inform economics. Journal of Economic Literature, 43, 9-64.

Cannon, P.R., Schnall, S., \& White, M. (2011). Transgressions and expressions: Affective facial muscle activity predicts moral judgments. Social Psychological and Personality Science, $2,325-331$.

Carver, C., \& Harmon-Jones, E. (2009). Anger is an approach-related affect: Evidence and implications. Psychological Bulletin, 135, 183-204.

Chapman, H., \& Anderson, A. (2012). Understanding disgust. Annals of the New York Academy of Sciences, 1251, 62-76.

Chapman, H., Kim, D., Susskind, J., \& Anderson, A. (2009). In bad taste: Evidence for the oral origins of moral disgust. Science, 323, 1222-1226.

De Martino, B., Camerer, C., \& Adolphs, R. (2010). Amygdala damage eliminates monetary loss aversion. Proceedings of the National Academy of Sciences, 107, 3788-3792.

Dreber, A., Fudenberg, D., \& Rand, D. (2014). Who cooperates in repeated games: The role of altruism, inequity aversion, and demographics. Journal of Economic Behavior \& Organization, 98, 41-55.

Dunn, B.D., Evans, D., Makarova, D., White, J., \& Clark, L. (2012). Gut feelings and the reaction to perceived inequity: The interplay between bodily responses, regulation, and perception shapes the rejection of unfair offers on the ultimatum game. Cognitive and Affective Behavioral Neuroscience, 12, 419-429.

Elster, J. (1998). Emotions and economic theory. Journal of Economic Literature, 36, 47-74. 


\section{EMOTIONS IN A REPEATED COURNOT DUOPOLY GAME}

Evans, A., Dillon, K., \& Rand, D. (2015). Fast but not intuitive, slow but not reflective: decision conflict drives reaction times in social dilemmas. Journal of Experimental Psychology: General, 144, 951-966.

Fehr, E., \& Fischbacher, U. (2002). Why social preferences matter: The impact of non-selfish motives on competition, cooperation and incentives. Economic Journal, 112, C1-C33.

Fessler, D., \& Haley, K. (2003). The strategy of affect: Emotions in human cooperation. In Hammerstein, P. (Ed.), Genetic and Cultural Evolution of Cooperation (pp. 7-36). Cambridge, MA: The MIT Press.

Fischer, A.H., \& Roseman, I.J. (2007). Beat them or ban them: The characteristics and social functions of anger and contempt. Journal of Personality and Social Psychology, 93, 103115.

Fouraker, L., \& Siegel, S. (1963). Bargaining Behavior. New York, NY: McGraw-Hill.

Fredrickson, B.L. (2001). The role of positive emotions in positive psychology: The broadenand-build theory of positive emotions. American Psychologist, 56, 218-226.

Fridlund, A., \& Cacioppo, J. (1986). Guidelines for human electromyographic research. Psychophysiology, 23, 567-589.

Fudenberg, D., \& Maskin, E., (1986). The folk theorem in repeated games with discounting or with incomplete information. Econometrica, 54, 533-554.

Haidt, J. (2007). The new synthesis in moral psychology. Science, 316, 998-1002.

Harlé, K., \& Sanfey, A. (2007). Incidental sadness biases social economic decisions in the ultimatum game. Emotion, 7, 876-881. 


\section{EMOTIONS IN A REPEATED COURNOT DUOPOLY GAME}

Hochman, G., \& Yechiam, E. (2011). Loss aversion in the eye and in the heart: The autonomic nervous system's responses to losses. Journal of Behavioral Decision Making, 24, 140156.

Holt, C. (1995). Industrial organization: A survey of laboratory research. In Kagel, J., \& Roth, A. (Eds.), Handbook of Experimental Economics (pp. 349-443). Princeton, NJ: Princeton University Press.

Huck, S., Müller, W., \& Normann, H-T. (2001). Stackelberg beats Cournot - On collusion and efficiency in experimental markets. Economic Journal, 111, 749-765.

Huck, S., Normann, H-T., \& Oechssler, J. (1999). Learning in Cournot oligopoly - An experiment. Economic Journal, 109, 80-95.

Huck, S., Normann, H. T., \& Oechssler, J. (2004). Two are few and four are many: number effects in experimental oligopolies. Journal of Economic Behavior \& Organization, 53, $435-446$.

Joffily, M., Masclet, D., Noussair, C.N., \& Villeval, M.C. (2014). Emotions, sanctions, and cooperation. Southern Economic Journal, 80, 1002-1027.

Kahneman, D., \& Tversky, A. (1984). Choices, values, and frames. American Psychologist, 39, $341-350$.

Krajbich, I., Oud, B., \& Fehr, E. (2014). Benefits of neuroeconomics modeling: New policy interventions and predictors of preference. The American Economic Review, 104, 501506.

Krajbich, I., Bartling, B., Hare, T., \& Fehr, E. (2015). Rethinking fast and slow based on a critique of reaction-time reverse inference. Nature Communications, 6, 7455. 


\section{EMOTIONS IN A REPEATED COURNOT DUOPOLY GAME}

Larsen, J., Norris, C., \& Cacioppo, J. (2003). Effects of positive and negative affect on electromyographic activity over zygomaticus major and corrugator supercilii. Psychophysiology, 40, 776-785.

Loewenstein, G., \& O’Donoghue, T. (2004). Animal spirits: Affective and deliberative processes in economic behavior. SSRN Working Papers May 4.

Loewenstein, G., Rick, S., \& Cohen, J. (2008). Neuroeconomics. Annual Review of Psychology, $59,647-672$.

Mason, C.F., \& Phillips, O.R. (1997). Information and cost asymmetry in experimental duopoly markets. Review of Economics and Statistics, 79, 290-299.

Miller, E., \& Cohen, J. (2001). An integrative theory of prefrontal cortex function. Annual Review of Neuroscience, 24, 167-202.

Nabi, R.L. (2002). The theoretical versus the lay meaning of disgust: Implications for emotion research. Cognition and Emotion, 16, 695-703.

Normann, H-T., Requate, T., \& Waichman, I. (2014). Do short-term laboratory experiments provide valid descriptions of long-term economic interactions? A study of Cournot markets. Experimental Economics, 17, 371-390.

Ochsner, K.N., Silvers, J.A., \& Buhle, J.T. (2012). Functional imaging studies of emotion regulation: A synthetic review and evolving model of the cognitive control of emotion. Annals of the New York Academy of Sciences, 1251, E1-E24.

Offerman, T. (2002). Hurting hurts more than helping helps. European Economic Review, 46, $1423-1437$. 
Phelps, E. (2009). The study of emotion in neuroeconomics. In Glimcher, P., Camerer, C., Fehr, E., \& Poldrack, R. (Eds.), Neuroeconomics: Decision Making and the Brain (pp. 233250). London, UK: Academic Press.

Pillutla, M., \& Murnighan, J. (1996). Unfairness, anger, and spite: Emotional rejections of ultimatum offers. Organizational Behavior and Human Decision Processes, 68, 208-224.

Piovesan, M., \& Wengström, E. (2009). Fast or fair? A study of response times. Economics Letters, 105, 193-196.

Potters, J., \& Suetens, S. (2009). Cooperation in experimental games of strategic complements and substitutes. The Review of Economic Studies, 76, 1125-1147.

Potters, J., \& Suetens, S. (2013). Oligopoly experiments in the current millennium. Journal of Economic Surveys, 27, 439-460.

Rassenti, S., Reynolds, S.S., Smith, V.L., \& Szidarovszky, F. (2000). Adaption and convergence of behavior in repeated experimental cournot games. Journal of Economic Behavior \& Organization, 41, 117-146.

Reuben, E., \& Suetens, S. (2012). Revisiting strategic versus non-strategic cooperation. Experimental Economics, 15, 24-43.

Roth, A.E. (1995). Introduction to experimental economics. In Kagel, J.H., \& Roth, A.E. (eds.), The Handbook of Experimental Economics, Princeton, NJ: Princeton University Press.

Roth, A.E., \& Murnighan, J.K. (1978). Equilibrium behavior and repeated play of the Prisoner's Dilemma. Journal of Mathematical Psychology, 17, 189-198.

Sanfey, A. (2007). Social decision-making: Insights from game theory and neuroscience. Science, 318, 598-602. 
Sanfey, A.G., Rilling, J.K., Aronson, J.A., Nystrom, L.E., \& Cohen, J.D. (2003). The neural basis of economic decision-making in the ultimatum game. Science, 300, 1755-1758.

Schmalensee, R. (1988). Industrial economics: An overview. Economic Journal, 98, 643-681.

Selten, R., Mitzkewitz, M., \& Uhlich, G. (1997). Duopoly strategies programmed by experienced players. Econometrica, 65, 517-555.

Sobel, J. (2005). Interdependent preferences and reciprocity. Journal of Economic Literature, 43, 392-436.

Society for Psychophysiological Research Ad Hoc Committee on Electrodermal Measures, (2012). Publication recommendations for electrodermal measurements. Psychophysiology, 49, 1017-1034.

Sokol-Hessner, P., et al. (2009). Thinking like a trader selectively reduces individuals' loss aversion. Proceedings of the National Academy of Sciences, 106, 5035-5040.

Sütterlin, S., Herbert, C., Schmitt, M., Küber, A., \& Vögele, C. (2011). Overcoming selfishness: Reciprocity, inhibition, and cardiac-autonomic control in the ultimatum game. Frontiers of Psychology, 2, 1-8.

Tassinary, L.G., Cacioppo, J-T., \& Vanman, E.J. (2007). The Skeletomotor System: Surface Electromyography. In Cacioppo, J-T., Tassinary, L.G., \& Berntson, G.G. (Eds.), Handbook of psychophysiology (pp. 267-299). New York, NY: Cambridge University Press.

Van Boxtel, A. (2010). Facial EMG as a tool for inferring affective states. In Spink, A.J. et al. (Eds.), Proceedings of Measuring Behavior (pp. 104-108). Eindhoven.

van’t Wout, M., Kahn, R.S., Sanfey, A.G., \& Aleman, A. (2006). Affective state and decisionmaking in the ultimatum game. Experimental Brain Research, 169, 564-568. 


\section{EMOTIONS IN A REPEATED COURNOT DUOPOLY GAME}

Vrana, S. (1993). The psychophysiology of disgust: Differentiating negative emotional contexts with facial EMG. Psychophysiology, 30, 279-286.

Xiao, E., \& Houser, D. (2005). Emotion expression in human punishment behavior. Proceedings of the National Academy of Sciences of the United States of America, 102, 7398-7401.

Zwick, R., Rapoport, A. (2002). Tacit coordination in a decentralized market entry game with fixed capacity. Experimental Economics, 5, 253-272. 


\section{EMOTIONS IN A REPEATED COURNOT DUOPOLY GAME}

Table 1

Estimation results for an LMM for the relationship between production quantity

adjustments between rounds $t-1$ and t and emotional activity during decision making

on round $t$

\begin{tabular}{lc} 
Independent variable & Estimate $(S E M)$ \\
\hline Intercept & $-0.049(-0.99)$ \\
Arousal & $2.1(1.43)$ \\
Decision time & $0.049(0.61)$ \\
Other defects & $1.1(5.3) * * *$ \\
Both cooperate & $0.36(1.4)$ \\
Ideal is equal & $-0.23(-1.1)$ \\
Arousal $\times$ other defects & $10.2(2.08) *$ \\
Decision time $\times$ other defects & $0.14(0.45)$ \\
Arousal $\times$ both cooperate & $4.3(0.68)$ \\
Decision time $\times$ both cooperate & $-0.13(-0.26)$ \\
Arousal $\times$ ideal is equal & $-3.1(-0.55)$ \\
Decision time $\times$ ideal is equal & $0.22(0.58)$ \\
$\sigma_{\mathrm{b}}$ & $4.4 \cdot 10-5$ \\
$\sigma$ & 1.92 \\
$\varphi_{1}$ & -0.44 \\
$\varphi_{2}$ & -0.25 \\
$D F$ & 673
\end{tabular}

Note: The log-transformed values of arousal and decision time are centered on subject means.

"Other defects" is a dummy coded variable that equals 1 if $x_{i}^{t-1}=6$ and $x_{j}^{t-1} \geq 8$ and 0

otherwise, where the superscript denotes round. "Both cooperate" is 1 if $x_{i}^{t-1}, x_{j}^{t-1}=6$ and 0

otherwise. "Ideal is equal" is 1 if the outcome was the ideal outcome on the previous round and 0 otherwise. Subjects enter the model as random effects. The model has an AR(2) correlation structure. The asterisks denote significance levels: $* P<0.05, * * * P<0.001$. 


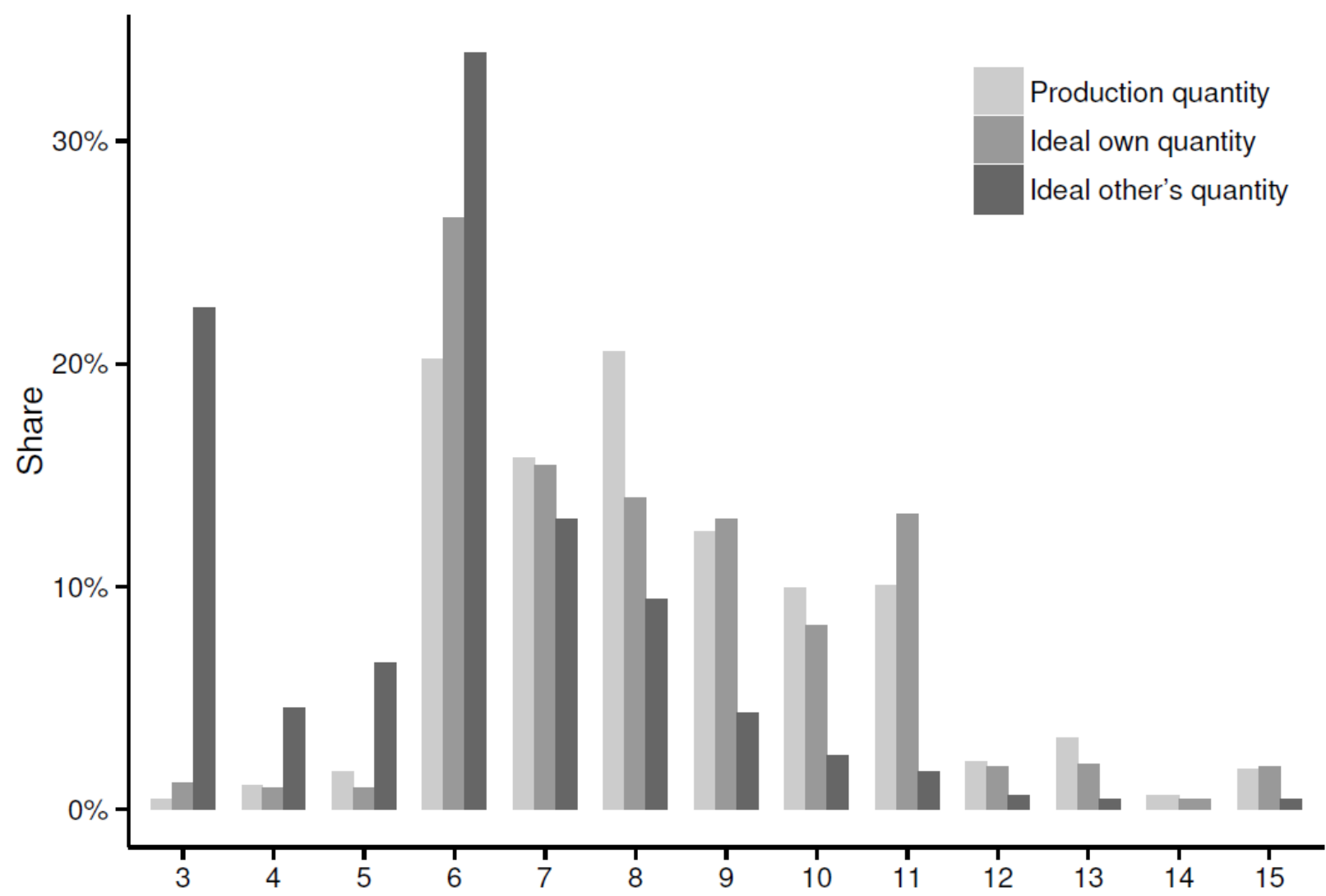

Figure 1. Share of production quantities, ideal own quantities, and ideal other's quantities $(N=$ 836) 
(a)

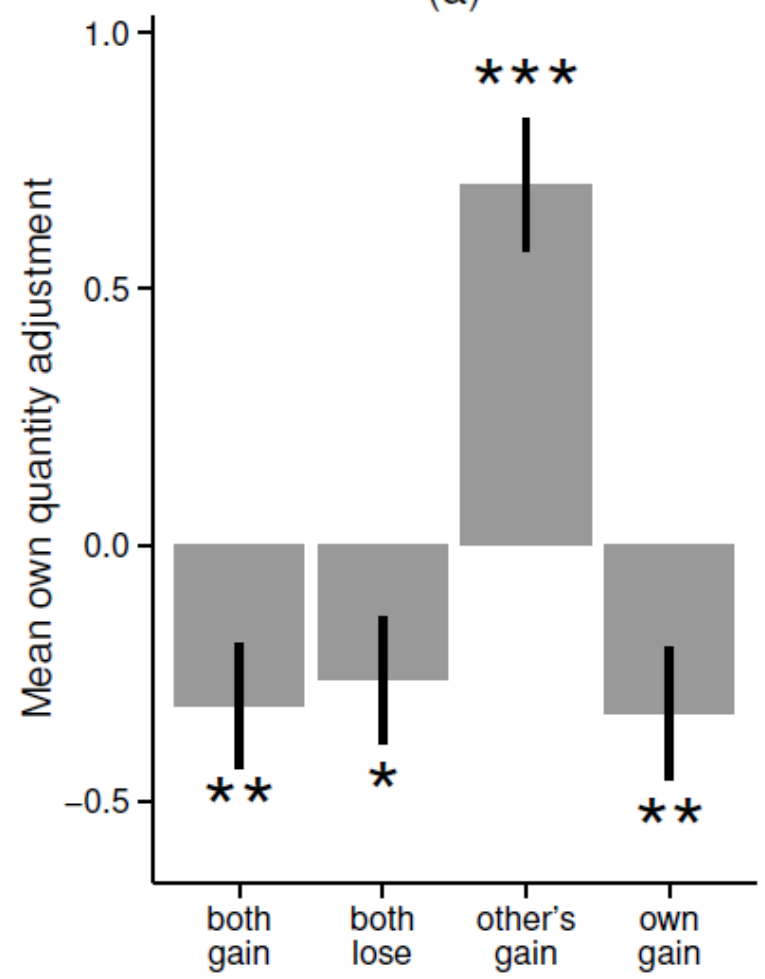

(b)

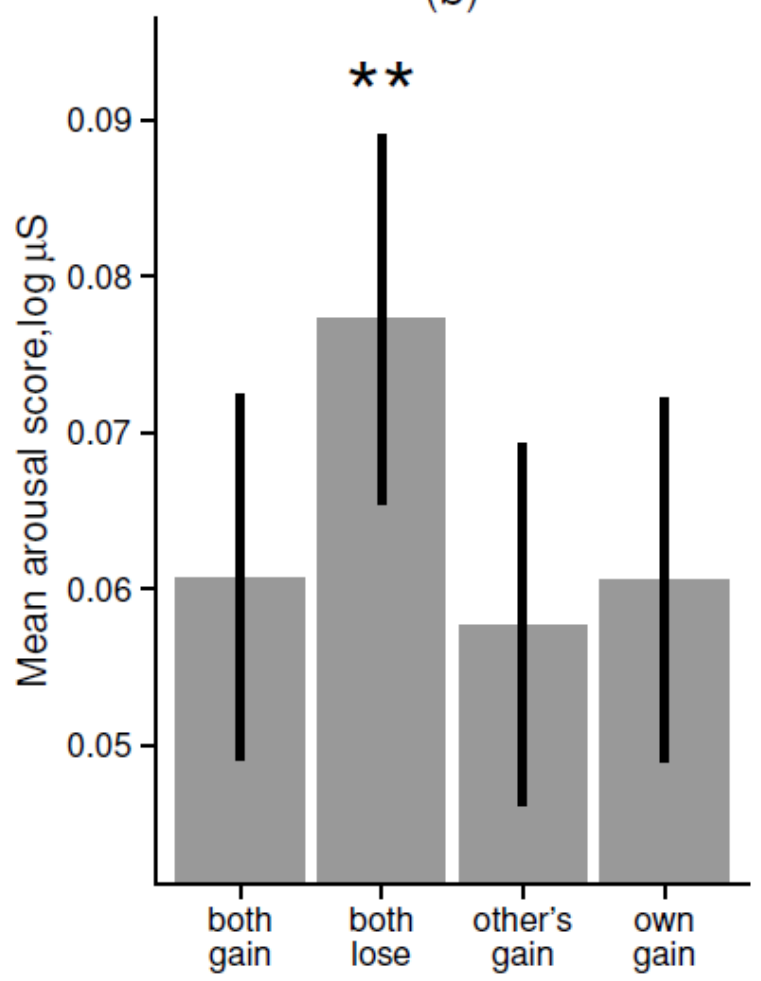

Figure 2. Behavioral and emotional reactions on changes in payoffs in a round. Bars show maximum likelihood estimation results from LMMs where the fixed effects are represented by deviation contrasts that indicate how the payoffs changed from round $t-1$ to round $t$. The error bars indicate $S E M \mathrm{~s}$. The significant contrasts are indicated with asterisks: $* P<0.05,{ }^{*} P<$ $0.01, * * * P<0.001$.

a) Mean own quantity adjustments $(N=792)$ between rounds $t-1$ and $t$. The LMM has an $\operatorname{AR}(2)$ correlation structure with parameter estimates $\varphi_{1}=-0.48, \varphi_{2}=-0.21$. The random effects are: $\sigma_{\mathrm{b}}=3.9 \cdot 10^{-5}, \sigma=2.00$.

b) Mean arousal scores $(N=722)$ on round $t, \log$ transformed. The LMM has an AR(1) correlation structure with a parameter estimate $\varphi_{1}=0.37$. The random effects are: $\sigma_{\mathrm{b}}=0.064, \sigma=$ 0.063 . 

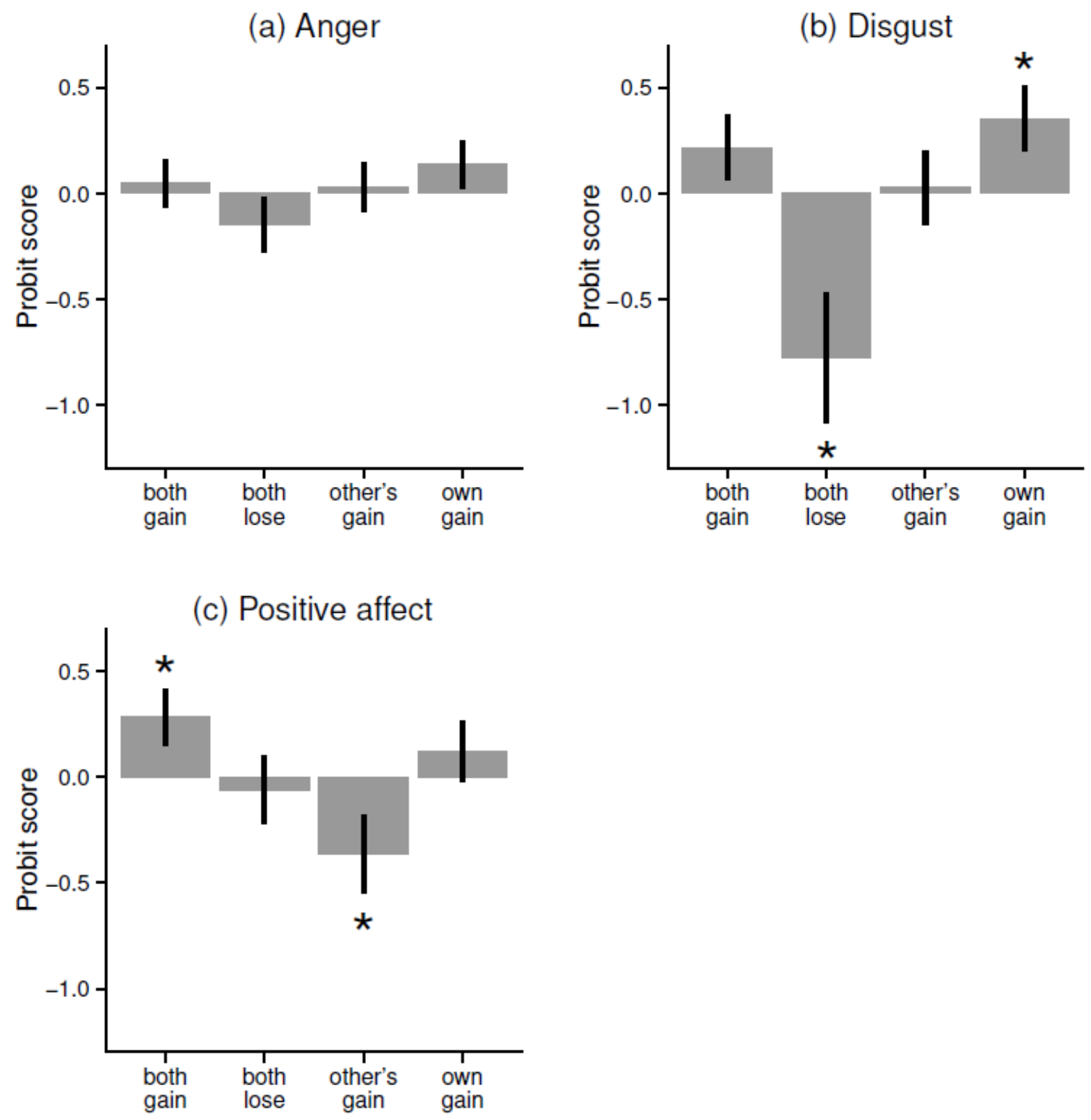

Figure 3. Facial emotional expressions on changes in payoffs in a round. The bar plots show maximum likelihood estimation results from GLMMs with Probit link functions where the round $t$ EMG count scores are the dependent variables and the fixed effects are represented by deviation contrasts that indicate how the payoffs change from round $t-1$ to round $t$. The error bars indicate SEMs. The significant contrasts are indicated with an asterisk: $* 0.01 \leq P<0.05$. The subjects enter the models as random effects, and the random effect estimates for the 


\section{EMOTIONS IN A REPEATED COURNOT DUOPOLY GAME}

intercepts are: a) $\left.\left.\sigma_{\mathrm{b}}=0.38, \mathrm{~b}\right) \sigma_{\mathrm{b}}=0.34, \mathrm{c}\right) \sigma_{\mathrm{b}}=0.22$. The Probit model has a constant random effect for the residual standard deviation $\sigma$. 